\title{
Self- care practices and associated factors among adult diabetic patients in public hospitals of Dire Dawa administration, Eastern Ethiopia
}

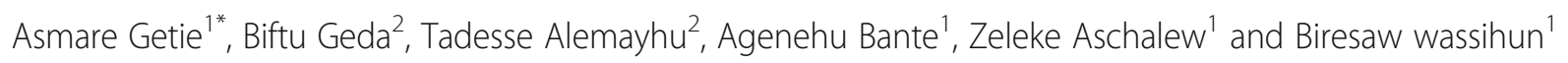

\begin{abstract}
Background: Diabetes is a huge growing problem, and causes high and escalating costs to society. Self- care practice for adults with diabetes is not well addressed in sub-Saharan Africa including Ethiopia. To prevent serious morbidity and mortality, diabetes treatment requires a commitment to demanding self-care practice. This study aimed to assess self- care practices and its associated factors among adults with diabetes in Dire Dawa public hospitals of Eastern, Ethiopia.

Methods: A cross-sectional study was conducted among 513 adults with diabetes. The study participants were selected through systematic random sampling. Data were collected from February 1st to March 1st, 2018. Patients were interviewed using a structured questionnaire. Data were entered into Epi-data version 3.3.1 and exported to SPSS version 22.0 for analysis. Bivariable and multivariable logistic regression with crude and adjusted odds ratios along with the $95 \%$ confidence interval was computed and interpreted accordingly. Good self-care was defined based on mean calculation; a result above the mean value had a good self-care practice, and a $P$-value of $<0.05$ was considered to declare a result as statistically significant.
\end{abstract}

Result: The result of the study showed that $55.9 \%$, $(95 \%$ Cl: $51.4,60.3)$ of participants had good self-care practices. Good self-care practice was associated with having family support, treatment satisfaction, diabetes education, having glucometer, higher educational status, duration of the disease, high economic status, and having good knowledge. Self-care practice was significantly associated with good diabetes knowledge (AOR=2.14, 95\% Cl: 1.37, 3.35), family support system ( $A O R=2.69,95 \% \mathrm{Cl}: 1.56,4.62)$, treatment satisfaction ( $A O R=2.07,95 \% \mathrm{Cl}: 1.18,3.62)$, diabetes education ( $\mathrm{AOR}=2.21,95 \% \mathrm{Cl}: 1.35,3.63)$, high economic status ( $\mathrm{AOR}=1.89,95 \% \mathrm{Cl}$ : 1.01, 3.48), having glucometer, $(A O R=2.69,95 \% \mathrm{Cl}: 1.57,4.63)$, higher educational status ( $A O R=2.68,95 \% \mathrm{Cl}: 1.31,5.49)$, and duration of disease greater than 10 years $\mathrm{AOR}=2.70,95 \% \mathrm{Cl}: 1.17,6.26)$.

Conclusion: In this study, a large number of adults had poor self-care practices which are very significant in controlling diabetes. Providing diabetes education, about self-care practices to the respondents and their families should be considerable.

Keywords: Diabetes mellitus, Self-care practice, Dire Dawa

\footnotetext{
* Correspondence: asmaregetie2017@gmail.com

${ }^{1}$ College of Medicine and Health Sciences, Arba Minch University, Arba Minch, Ethiopia

Full list of author information is available at the end of the article
}

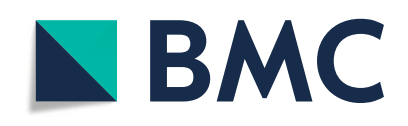

(- The Author(s). 2020 Open Access This article is licensed under a Creative Commons Attribution 4.0 International License, which permits use, sharing, adaptation, distribution and reproduction in any medium or format, as long as you give appropriate credit to the original author(s) and the source, provide a link to the Creative Commons licence, and indicate if changes were made. The images or other third party material in this article are included in the article's Creative Commons licence, unless indicated otherwise in a credit line to the material. If material is not included in the article's Creative Commons licence and your intended use is not permitted by statutory regulation or exceeds the permitted use, you will need to obtain permission directly from the copyright holder. To view a copy of this licence, visit http://creativecommons.org/licenses/by/4.0/. The Creative Commons Public Domain Dedication waiver (http://creativecommons.org/publicdomain/zero/1.0/) applies to the data made available in this article, unless otherwise stated in a credit line to the data. 


\section{Background}

Self-car is an individual's adherence to a diabetes selfmanagement regime, which is imperative to maintain glycemic control all-encompassing of diet, maintaining physical activity, daily monitoring of blood glucose levels, adhering to medication therapy and foot care [1]. Self-care is considered crucial for all people with diabetes for monitoring the disease process, prevention of complications, and glycemic control which improved quality of life [2].

Globally, an estimated 422 million adults were living with diabetes in 2014 [3]. Two-thirds of the global diabetes population lives in the developing world [4]. Based on the IDF Atlas 9th edition, the number of cases of diabetes globally was 463 million and Ethiopia was estimated at 1.7 million in 2019 [5]. Diabetes is one of the most challenging health problems in the twenty-first century. It costs at least 548 billion dollars in health expenditure in 2013 which is $11 \%$ of total health spending on adults [6]. When it is not prevented and properly managed, diabetes is one of the major causes of premature illness and death worldwide which resulted in 5.1 million deaths in 2013. Poor self-care practice increases the incidence and prevalence of complications resulting in increased morbidity, and mortality [7] To reduce morbidity and mortality different studies were conducted in different parts of the world. Although there was significant variation across countries, self-care practice on diabetes is less than optimal in all countries. More than one-third of US adults with diabetes have poor self-care practices [8]. Diabetic's self-care practices in Ethiopia is still low, which is in the range of $39-63.3 \%$ [9]. Despite the great strides that have been made in the treatment of diabetes in recent years, many patients do not achieve optimal outcomes and still experience devastating complications due to inadequate self-care practice, and there is little information in the study area. Hence the finding of the study provides and fills the gap-related to the level of self-care practice. Therefore, this study aims to assess self-care practices and its associated factors among adults with diabetes in Dire Dawa city Administration Eastern Ethiopia.

\section{Methods}

\section{Study area and period}

The study was conducted in Dire Dawa Administrative city from the1st of February to the 1st of March 2018. Dire Dawa is located in the Eastern part of the country enclosed by Ethiopian Somalia and the State of Oromia. It is $515 \mathrm{~km}$ from Addis Ababa and $47 \mathrm{~km}$ from Harar town. It has a hot temperature with a mean of 25 degrees centigrade. Based on the 2007 Census, the total population of Dire Dawa Administrative city is 395,000 of which females account $51.6 \%$.
It has 9 urban kebeles (small administrative units of Ethiopia) and 38 rural kebeles. The City has given health care services for the catchment population in different disciplines. The hospitals have provided services for adults with diabetes in the diabetic clinic. The service is given by physicians, and 2171 adults with diabetes were registered for follow-up in the past one year.

\section{Study design}

Institutional based cross-sectional study design was conducted.

\section{Inclusion and exclusion criteria Inclusion criteria}

All adults with diabetes who had one year follow up and came into diabetic clinics were included in the study.

\section{Exclusion criteria}

Those adults with diabetes who are critically and mentally ill, pregnant women's and newly diagnosed adults with diabetes were excluded.

\section{Sample size determination and sampling procedures}

The required sample size is determined by using a formula for single population proportion by taking different $p$ values from different studies; and the sample size for some of the factors for diabetic self-care practices obtained from different pieces of literature was calculated by Epi Info 7 menu statically, by considering the following assumptions: confidence level $95 \%$, power $80 \%$ and exposed to the unexposed ratio of 1 . So, the sample size for this study was 466 and after adding a non-response rate of $10 \%$ the final sample size became 513 .

\section{Sampling procedures}

In the study area there are two governmental hospitals (SGH=Sabian General Hospital and DCRH = Dill Chora referral hospital) and these two governmental hospitals were selected purposively. These two hospitals have separate clinics for diabetes follow-up. The number of study participants from the selected health facilities was determined from the previous total number of diabetic patients who have followed up which is 2171 in the two hospitals.

Samples were allocated to each of the selected hospitals based on proportional allocation to sample size. The lists of respondents or sampling frames were obtained from the updated registration books of each follow-up clinic of the hospitals. After establishing the sampling frames of respondents, a simple random sampling technique was used to identify the study unit to be included in the study. Adults with Diabetes were selected by computer method using updated registration books as a sampling frame until a sample of 513 was reached. 


\section{Data collection tools}

Six trained nurses conducted the interview using a structured pretested questionnaire for one month. The principal investigator and an assistant supervised the data collection. Face to face interviewer-administered validated questionnaire was used to measure self-care practice, which was contextualized to the study area. It was prepared originally in English and was translated to Amharic, and then translated back to English for checking the consistency of the questionnaire. The questionnaire consisted of socio-demographic variables (8 items), health-related variables (14 items), diabetic knowledge (15 items), treatment satisfaction (6 items), and self-care practice (15 items).

\section{Data collection technique}

The data collection was conducted in an institutionbased exit interview by using pre-tested Amharic, and English questionnaires. The training was provided for the data collectors and supervisors by the principal investigator. All adults with diabetes who are selected and fulfill the inclusion criteria were interviewed. Confidentiality and privacy were kept.

\section{Data analysis}

The collected data were cleaned, coded, and entered into Epi Data 3.3.1 statistical software package. The statistical analysis was done using SPSS version 22 . Frequency distribution for selected variables was done. The statistical significance and strength of the association between independent variables and an outcome variable were measured by the bivariate logistic regression model. A variable $P$-value less than 0.2 was candidates to multivariable logistic regression model and a $p$-value less than 0.05 was considered as significantly associated. Finally, the results of the study were presented using tables, figures, and texts based on the data obtained.

\section{Operational definitions Self-care practices}

It is the practice of activities that individual diabetics will initiate and perform on their behalf in controlling their disease, maintaining life, health, and wellbeing [10].

\section{Good self-care practices}

individuals who have scored mean and above the mean value of the total 15 self-care practice questions. These 15 items evaluate the status of patients' self-care during the last seven days. Responses in each subscale were based on 7-days, ranged from 0 to 7 , the higher number was indicative of days reflecting better self-care operation. The minimum score is 0 and the maximum score in this tool is 105, which is indicative of the highest quality of self-care.

\section{Knowledge about diabetes}

This is measured by fifteen items in yes/no format. The correct answer will be given " 1 " and " 0 " is given for incorrect and don't know. Then a total score is computed out of fifteen marks (with the range of $0-15$ ) those who score mean and above the mean have a good knowledge whereas those who score below the mean value have no good knowledge [11].

\section{Results}

Socio-demographic characteristics of the participants

A total of 513 diabetic patients were approached, among which all, but 7 consented and complete the interview. The seven interviewees consented, but could not finish the interview, giving a $98.6 \%$ response rate. From the total respondents, 279 (55.1\%) were females and $227(44.9 \%)$ were males. More than half of the respondents (56.7\%) were Orthodox, 170(33.6\%) Muslims, and 47(9.3\%) Protestants, regarding ethnicity 217 (42.9\%) were Amhara and 190 (37.5\%) were Oromo. More than half of the respondents (54.5\%) were married, 71(14\%) single, 53 (10.5\%) widowed, and 106(20.9) were separated. The Mean age of the respondents was 51.48 (SD \pm 14.75) years with a range of 18 to 86 years. From the total respondents one hundred seventy-two $(34 \%)$ were self-employed (Table 1).

\section{Health status of the study participants}

The majority of the respondents, 378 (74.7\%) were type 2 diabetic patients, $60.7 \%$ of the respondents had no history of co-morbidities, and most of the patients (61.3\%) were on oral hypoglycemic agents and $24.3 \%$ were on insulin medication.

Only $34(6.7 \%)$ of the participants were members of the Ethiopian Diabetes Association. The majority of the participants (77.5\%) had family support. About 231 (45.7\%) of the participants usually received diabetes education and more than half of the participants (53.6\%) were knowledgeable. The diabetic treatment satisfaction rate was $81.6 \%$ (Fig. 1).

From the total respondents, one hundred fifty-one (29.8\%) had a family history of diabetes and nearly onefifth of the respondents (18.8\%) had glucometer at home. More than one-third of the participants 199 (39.3\%) had long term diabetic complications confirmed medically and almost all 187(94\%) have hypertension (Table 2).

\section{The magnitude of self care practices}

Overall self-care practices were calculated using 15 selfcare assessment tools with a total score of 105 . Using this, the overall mean score for self-care was $43.5(\mathrm{SD} \pm$ 10.9 ) and range from19-69 points. Two hundred eightythree subjects $(55.9 \%)$ scored above the mean value from 
Table 1 Socio-demographic data of adult diabetic patients in Dire Dawa public hospitals 2018, $(n=506)$

\begin{tabular}{|c|c|c|c|}
\hline \multirow[t]{2}{*}{ Characteristics } & \multirow[t]{2}{*}{ Alternative response } & \multicolumn{2}{|c|}{ Frequency } \\
\hline & & No & $\%$ \\
\hline \multirow[t]{2}{*}{$\overline{S e x}$} & Male & 227 & 44.9 \\
\hline & Female & 279 & 55.1 \\
\hline \multirow[t]{5}{*}{ Ethnicity } & Amhara & 217 & 42.9 \\
\hline & Oromo & 190 & 37.5 \\
\hline & Tigre & 17 & 3.4 \\
\hline & Gurgie & 53 & 10.5 \\
\hline & Somali & 29 & 5.7 \\
\hline \multirow[t]{4}{*}{ Religion } & Orthodox & 287 & 56.7 \\
\hline & Muslim & 170 & 33.6 \\
\hline & Protestant & 47 & 9.3 \\
\hline & Other & 2 & .4 \\
\hline \multirow[t]{4}{*}{ Marital status } & Married & 276 & 54.5 \\
\hline & Single & 71 & 14 \\
\hline & Widowed & 53 & 10.5 \\
\hline & Separated & 106 & 20.9 \\
\hline \multirow[t]{5}{*}{ Level of education } & Cannot read cannot write & 130 & 25.7 \\
\hline & Read and write & 70 & 13.8 \\
\hline & Primary school & 101 & 20 \\
\hline & Secondary school & 120 & 23.7 \\
\hline & College and above & 85 & 16.8 \\
\hline \multirow[t]{5}{*}{ Occupation } & Self-employed & 172 & 34 \\
\hline & Employed & 105 & 20.8 \\
\hline & Unemployed & 161 & 31.8 \\
\hline & Student & 26 & 5.1 \\
\hline & Housewife & 42 & 8.3 \\
\hline \multirow[t]{3}{*}{ Wealth index } & Low & 170 & 33.6 \\
\hline & Medium & 193 & 38.1 \\
\hline & High & 143 & 28.3 \\
\hline
\end{tabular}

the total self-care questions. As a result, $55.9 \%$, (95\% CI: $51.4,60.3)$ have good self-care practices.

Regarding adherence to regular exercise, 294 (58.1\%) of the respondents adhered to the recommended daily regular exercise; nearly more than half $(53.8 \%)$ of the respondents practiced a physical activity of at least $30 \mathrm{~min}$ on all days of the week and twenty-five (5\%) had A separate exercise session more than 3 days per week apart from their day to day physical activities.

Regarding medication, the majority $(91.7 \%)$ of the study participants adhered to the prescribed medication on all days of the week. The majority, $(78.5 \%)$, of the respondents, didn't practice the recommended self -monitoring of blood Glucose which means, monitoring their blood sugar level less than the mean value.
More than half $(54.9 \%)$ of the study participants did not adhere to the recommended diet management practices which means below the mean value. Around twothirds $(62.1 \%)$ of the respondents had practiced the recommended diabetic foot care, which scored mean and above the mean. From the total respondents, 386 (76.3\%) had washed their feet all days of the week, 273 (54\%) of diabetic patients had checked their feet on all days of the week. More than half, (55.7\%), of the respondents, performed daily foot inspection, and nearly greater than half $(51 \%)$ of respondents reported that they dried between their toes after washing their feet (Table 3).

\section{Discussion}

In this study, the current self-care practices of peoples with diabetes in Dire Dawa public hospitals and factors that contribute to the self-care practice of diabetics were investigated. The finding of this study was addressed factors that were not well studied by other studies like foot care practice and it provides pertinent information to the population in the study area as well for the scientific society since there were no previous local studies. Overall, Self-care practices among people with diabetes were found to be good at 55.9\%, (95\% CI: 51.4, 60.3) of the study participants.

The predictors of self-care practices were: getting an education from health professions, having glucometer at home, having knowledge about diabetes, treatment satisfaction, duration of disease, having family support, educational status, and family wealth index.

The overall recommended self-care practice was (55.9\%). This finding was in line with the results of the studies conducted in Addis Ababa (60.2\%) [12]. However, the finding of this study was greater than the study conducted in Harar, Eastern Ethiopia (39.2\%) [13]. This discrepancy may be due to some improvements in the health care systems (related to the period gap) and variation of cutoff point to classify good and poor self-care, mean, and $50 \%$ of total self-care practices, respectively. Sample size variation may also attribute to this difference.

On the contrary, the finding of this study was lower than the study conducted in Eastern Nepal of which (70\%), of the study participants, had good self-care practices [14]. This variation could be due to socio-cultural differences. The majority of the study participants in Nepal had a high income, so that they could afford their own glucometer and easily get a healthy diet. This finding is also lower than the study which was conducted in Dilla, South Ethiopia which had $76.8 \%$ good self-care practices. Methodological and sample size variation may also account for this discrepancy [11].

This study revealed that those who had family support were nearly three times more likely to have good self- 


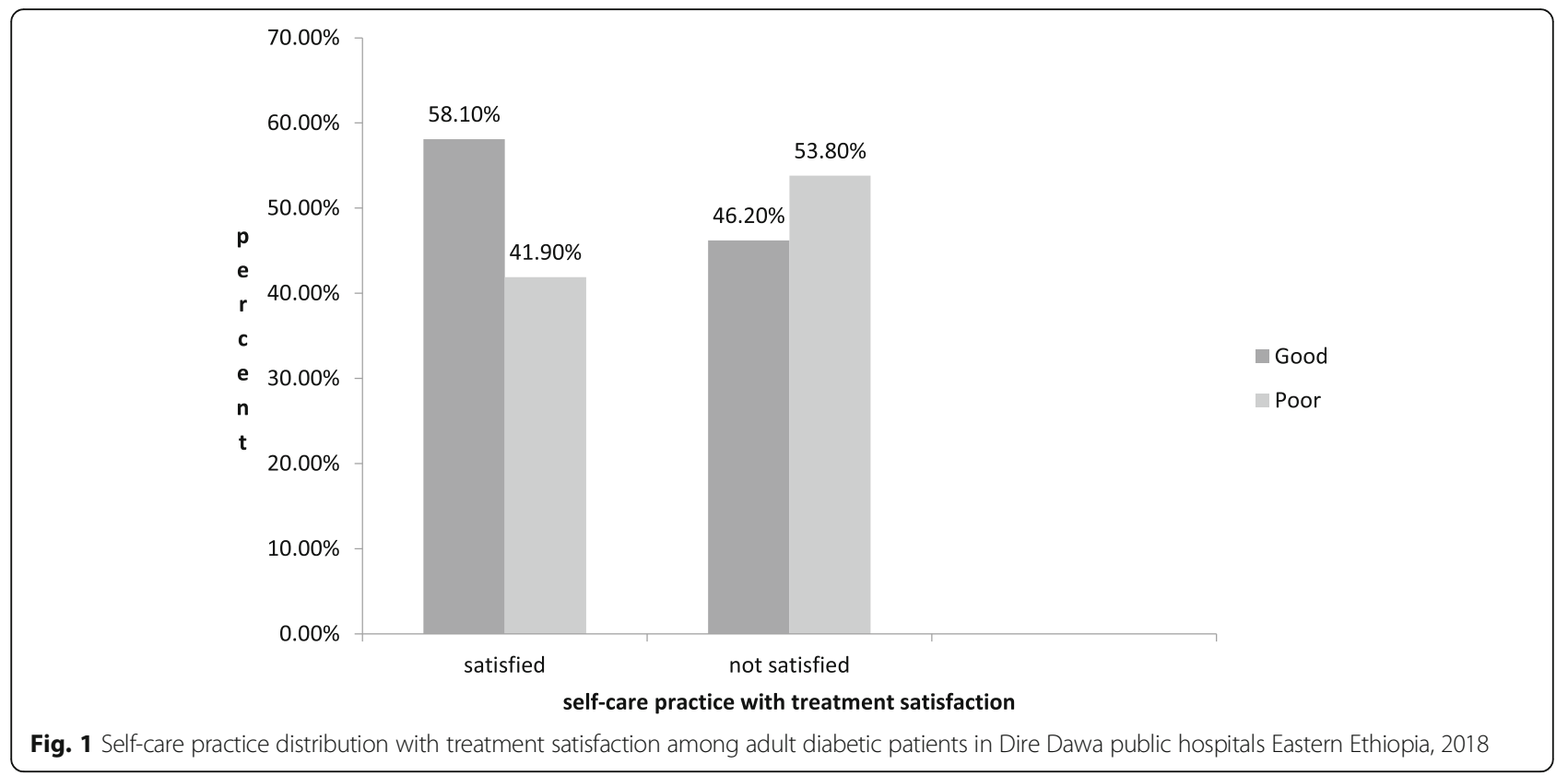

Table 2 Health status data of type 2 diabetes patients in Dire Dawa public hospitals, $2018(n=506)$

\begin{tabular}{|c|c|c|c|}
\hline \multirow[t]{2}{*}{ Characteristics } & \multirow[t]{2}{*}{ Alternative response } & \multicolumn{2}{|c|}{ Frequency } \\
\hline & & $\overline{\text { No }}$ & $\%$ \\
\hline \multirow[t]{2}{*}{ Knowledge of diabetes } & Good & 271 & 53.6 \\
\hline & Poor & 235 & 46.4 \\
\hline \multirow[t]{3}{*}{ Duration of diabetes } & $1-5$ years & 215 & 42.5 \\
\hline & $6-10$ years & 240 & 47.4 \\
\hline & Greater than 10 years & 51 & 10.1 \\
\hline \multirow[t]{2}{*}{ Comorbidities } & Yes & 199 & 39.3 \\
\hline & No & 307 & 60.7 \\
\hline \multirow[t]{3}{*}{ Current treatment } & Oral & 310 & 61.3 \\
\hline & Insulin & 123 & 24.3 \\
\hline & Both & 73 & 14.4 \\
\hline \multirow[t]{2}{*}{ Having glucometer } & Yes & 93 & 18.38 \\
\hline & No & 413 & 81.62 \\
\hline \multirow[t]{2}{*}{ Getting DM education } & Yes & 231 & 45.7 \\
\hline & No & 275 & 44.3 \\
\hline \multirow[t]{2}{*}{ Members of Diabetes association } & Yes & 34 & 6.7 \\
\hline & No & 472 & 93.3 \\
\hline \multirow[t]{2}{*}{ Treatment satisfaction } & Yes & 413 & 81.6 \\
\hline & No & 93 & 18.4 \\
\hline \multirow[t]{2}{*}{ Having family support } & Yes & 392 & 77.5 \\
\hline & No & 114 & 22.5 \\
\hline \multirow[t]{2}{*}{ Having support from society } & Yes & 19 & 3.8 \\
\hline & No & 487 & 96.2 \\
\hline \multirow[t]{2}{*}{ Alcohol drinking } & Yes & 35 & 6.9 \\
\hline & No & 471 & 93.1 \\
\hline
\end{tabular}

care practices than those who did not. This is consistent with a study conducted in Addis Ababa [12] and Kenya [15]. Individuals who have family support could have better information related to disease, have a chance to get an education, and may have got a good income.

Those who had received education from health care professionals were almost two times more likely to have good self-care practice than those who didn't. This finding was comparable with the study conducted in Addis Ababa [12] and Harari [13].

Respondents who had a higher level of education were nearly three times more likely to be engaged in self-care practices when compared with respondents who were unable to read and write. This finding was congruent with the studies conducted in Black Lion, hospital, and study conducted in Gondar [7, 12]. This implies that education is the base for a diabetic patient to understand the disease process and to provide own self-care practice, because they may be able to read and become more informed of the benefits of adherence.

Knowledge of diabetes and its disease process was found to be positively associated with self-care practice. Individuals who were knowledgeable were nearly two times more likely to have good self-care practice than those who had less diabetes knowledge. This finding was in line with the finding from Addis Ababa, Malaysia, and the Harari Region of Eastern Ethiopia [8, 12, 13]. The possible justification is that the right knowledge about diabetes and its self-care practice creates a clear understanding and avoids confusion about the practice and the disease condition.

Respondents who have glucometer at home were nearly three times more likely to have good self-care 
Table 3 Self-care practices among adults with diabetes and factors associated with self-care in Dire Dawa public hospitals, 2018

\begin{tabular}{|c|c|c|c|c|}
\hline \multirow[t]{2}{*}{ Variables } & \multicolumn{2}{|c|}{ Self-care practice } & \multirow[t]{2}{*}{ COR; $95 \% \mathrm{Cl}$} & \multirow[t]{2}{*}{ AOR; $(95 \% \mathrm{Cl}$} \\
\hline & Good N (\%) & Poor N (\%) & & \\
\hline \multicolumn{5}{|c|}{ Duration of disease in Year } \\
\hline $1-5$ & $16(39)$ & $25(61)$ & 1.00 & 1.00 \\
\hline $6-10$ years & $90(51.75)$ & $84(48.3)$ & $0.146(0.84-3.35)$ & $1.56(0.99-2.46)$ \\
\hline$>10$ years & $177(60.8)$ & 114(39.2) & $2.426(1.24-4.74)$ & $3.339(1.51-7.38)$ \\
\hline \multicolumn{5}{|l|}{ DM Education } \\
\hline Received & $153(66.2)$ & 78(33.8) & $2.188(1.52-3.13)$ & $2.20(1.34-3.62)^{*}$ \\
\hline Not received & $130(47.3)$ & $145(52.7)$ & 1.00 & 1.00 \\
\hline \multicolumn{5}{|l|}{ Sex } \\
\hline Male & $143(63)$ & $84(37)$ & 1.00 & 1.00 \\
\hline Female & $140(50.2)$ & 139(49.8) & $1.69(1.182-2.416)$ & $0.906(0.55-1.48)$ \\
\hline \multicolumn{5}{|l|}{ Disease knowledge } \\
\hline Good & 188(69.4) & 83(30.6) & $3.338(2.31-4.81)$ & $2.144(1.37-3.34)^{*}$ \\
\hline poor & $95(40.4)$ & 140(59.6) & 1.00 & 1.00 \\
\hline \multicolumn{5}{|l|}{ Glucometer at home } \\
\hline Yes & 78(83.9) & $15(16.1)$ & $5.27(2.93-9.47)$ & $2.69(1.56-4.62)^{*}$ \\
\hline No & 205(49.6) & $208(50.4)$ & 1.00 & 1.00 \\
\hline \multicolumn{5}{|l|}{ Mode of treatment } \\
\hline Tablet & 167(53.9) & $143(46.1)$ & 1.00 & 1.00 \\
\hline Insulin & 116(59.2) & $80(40.8)$ & $0.80(0.56-1.15)$ & $0.97(0.61-1.54)$ \\
\hline \multicolumn{5}{|l|}{ Educational level } \\
\hline Not read and write & $62(47.7)$ & $68(52.3)$ & 1.00 & 1.00 \\
\hline Read and write & $26(37.1)$ & $44(62.9)$ & $0.64(0.35-1.17)$ & $0.77(0.36-1.63)$ \\
\hline Elementary school & $58(57.4)$ & $43(42.6)$ & $1.48(0.87-2.49)$ & $1.55(0.75-3.17)$ \\
\hline Secondary school & $74(61.7)$ & $46(38.3)$ & $1.764(1.066-2.92)$ & $1.95(0.95-3.95)$ \\
\hline College and above & $63(74.1)$ & $22(25.9)$ & $3.14(1.73-5.69)$ & $2.70(1.17-6.25)^{*}$ \\
\hline \multicolumn{5}{|l|}{ Marital status } \\
\hline Married & $162(58.7)$ & $114(41.3)$ & $1.53(0.97-2.49)$ & $0.77(0.42-1.39)$ \\
\hline Single & $44(62)$ & $27(38)$ & $1.75(0.78-3.21)$ & $0.859(0.36-2.00)$ \\
\hline Widowed & $26(49.1)$ & $27(50.9)$ & $1.038(0.53-2.00)$ & $0.747(0.33-1.69)$ \\
\hline Separated & $51(48.1)$ & $55(51.9)$ & 1.00 & 1.00 \\
\hline \multicolumn{5}{|l|}{ Family support } \\
\hline Having & $246(62.8)$ & $146(37.2)$ & $2.28(1.52-3.43)$ & $2.69(1.56-4.62)^{*}$ \\
\hline Not having & $37(32.5)$ & $77(67.5)$ & 1.00 & 1.00 \\
\hline \multicolumn{5}{|l|}{ Treatment satisfaction } \\
\hline Satisfied & $240(58.1)$ & 173(41.9) & $1.61(1.02-2.53)$ & $2.06(1.18-3.61)^{*}$ \\
\hline Not satisfied & $43(46.2)$ & $50(53.8)$ & 1.00 & 1.00 \\
\hline \multicolumn{5}{|l|}{ Wealth index } \\
\hline Low & $76(44.7)$ & $94(55.3)$ & 1.00 & 1.00 \\
\hline Medium & $123(63.7)$ & $70(36.3)$ & $2.1(1.42-3.31)$ & $1.47(0.85-2.53)$ \\
\hline High & $84(58.7)$ & $59(41.3)$ & $1.76(1.12-2.76)$ & $1.88(1.02-3.47)$ \\
\hline
\end{tabular}


practice when compared to those who didn't. This finding was in line with the finding of the study which was conducted in Black Lion Specialized Referral Hospital, Addis Ababa [4].

In this study participants who had high income were two times more likely to have good self-care practices than those who had low income. This finding was in line with the study conducted in Dilla University Referral Hospital and Arba Minch General Hospital [10, 11].

Respondents who were satisfied regarding treatment were nearly two times more likely to have good self-care practices than their counterparts. This finding was congruent with a study conducted in Nigeria [16]. Since patient satisfaction is directly associated with the degree of satisfaction with expected care and is linked with cognitive evaluation and emotional reactions to the components of care services.

\section{Conclusions}

In this study, a large number of adults had poor self-care practices which are very significant in controlling diabetes. Providing diabetes education, about self-care practices to the respondents and their families should be considerable. Subjects who had no glucometer, lack of family support, low educational status, low diabetes education, low economic status, and poor diabetes knowledge were negatively associated with self-care practice.

The hospital administration should stress on educating clients more during follow up periods and diabetic selfcare should be incorporated in the health education program of the hospitals.

Healthcare professionals should use precise and clear ways to provide information for respondents and their families to emphasis on dietary management.

Interventional studies are recommended to determine the outcome of the information provided on diabetes self-care practices of adults with diabetes.

\section{Abbreviations}

DM: Diabetes mellitus: confidence interval; AOR: Adjusted odds ratio; IDF: International diabetes federation; SMBG: Self-monitoring of Blood Glucose; US: United States

\section{Acknowledgments}

Not applicable.

\section{Authors' contributions}

AG designed the study, drafted the paper, supervised the data collection, performs analysis and interpretation of the results, and participated in preparing all versions of the manuscript. $A B, B G, T A, B W$, and $Z A$ assisted in the design and in the proposal development, monitored data collection, assisted during analysis, and revised subsequent drafts of the paper. All authors read and approved the final manuscript.

\section{Availability of data and materials}

The datasets used and/or analyzed during the current study are available from the corresponding author on reasonable request.

\section{Ethics approval and consent to participate}

Officially written approval letter was obtained from the Institutional Health Research Ethical Review Committee (IHRERC) of the College of Health and Medical Sciences, Haramaya University. Besides, an official letter was issued from the College of Health and Medical Sciences, Haramaya University to the director of each hospital. After securing permission from each hospital administrator, the actual data collection commenced after obtaining written and signed voluntary consent from each study participant. All information collected from the participants was kept confidential.

\section{Consent for publication}

Not applicable.

\section{Competing interests}

The authors declare that they have no competing interests.

\section{Author details}

${ }^{1}$ College of Medicine and Health Sciences, Arba Minch University, Arba Minch, Ethiopia. ${ }^{2}$ School of Nursing and Midwifery, Department of public health, College of Health and Medical Sciences, Haramaya University, Harar, Ethiopia.

Received: 15 August 2019 Accepted: 3 August 2020

Published online: 12 August 2020

\section{References}

1. Murri M, Insenser M, Bernal-Lopez MR, Perez-Martinez P, Escobar-Morreale HF, Tinahones FJ. Proteomic analysis of visceral adipose tissue in pre-obese patients with type 2 diabetes. Mol Cell Endocrinol. 2013;376(1-2):99-106.

2. Norris SL, Nichols PJ, Caspersen CJ, Glasgow RE, Engelgau MM, Jack L Jr, et al. The effectiveness of disease and case management for people with diabetes: a systematic review. Am J Prev Med. 2002;22(4):15-38.

3. World Health Organization. Global status report on noncommunicable diseases 2014. World Health Organization; 2014.

4. Chaurasia B, Summers SA. Ceramides-lipotoxic inducers of metabolic disorders. Trends Endocrinol Metab. 2015;26(10):538-50.

5. IDF Diabetes Atlas 9th edition. ISPAD guidelines for diabetes in childhood and adolescence. International diabetes federation. Centers of Excellence in Diabetes Care 2018-2019, ISBN: 978-2-930229-87-4.

6. Association AD. Standards of medical care in diabetes-2014. Diabetes Care. 2014;37(1):14-80.

7. Abebaw M, Messele A, Hailu M, Zewdu F. Adherence and associated factors towards antidiabetic medication among type II diabetic patients on followup at University of Gondar Hospital, Northwest Ethiopia. Adv Nursing. 2016; volume 2016.Article 8579157 pp 7 https://doi.org/https://doi.org/10.1155/ 2016/8579157.

8. Gunggu A, Thon CC, Whye Lian C. Predictors of diabetes self-management among type 2 diabetes patients. J Diabetes Res. 2016;2016(7). https://doi. org/10.1155/2016/9158943

9. Mamo M, Demissie M. Self care practice and its associated factors among diabetic patients in Addis Ababa public hospitals, cross-sectional study. J Diabetes Cholest Metabol. 2016;1(1):2-5

10. Sorato MM, Tesfahun C, Lamesa D. Levels and predictors of adherence to self-care behavior among adult type 2 diabetics at Arba Minch general hospital, Southern Ethiopia. J Diabetes Metab. 2016:7(6):11.

11. Addisu Y, Eshete A, Hailu E. Assessment of diabetic patient perception of diabetic disease and self-care practice in Dilla University referral hospital, South Ethiopia. J Metabolic Synd. 2014;3(166):2167-0943.1000166.

12. Alemayehu T, Geda B, Mihret AG. Self-care practices and associated factors among adult diabetic patients in public hospitals of Dire Dawa administration. Eastern Ethiopia: Haramaya University; 2018.

13. Ayele K, Tesfa B, Abebe L, Tilahun T, Girma E. Self care behavior among patients with diabetes in Harari, eastern Ethiopia: the health belief model perspective. PLoS One. 2012;7(4):e35515.

14. Chaurasia N, Mishra R, Ling H, Thapa B, Pokhara A, Kumar S, et al. A self-care management awareness study among diabetes mellitus patients in rural Nepal. Am J Public Health Res. 2015;3(5A):67-71.
Funding

Not applicable. 
15. Lugaya WA, Mwenda CS, Affey FA. Self-care practices among diabetes mellitus type II patients attending the diabetes clinic of a referral hospital in Kenya. Kenyan J Nursing Midwifery. 2017;1 (2):1.

16. Pascal IGU, Nkwa AA. Diabetes treatment satisfaction, medication adherence, and glycemic control among ambulatory type 2 diabetic Nigerians in a primary care clinic of a tertiary hospital situated in a resource-limited environment of Southeast Nigeria. Arch Med Health Sci. 2016;4(2):169.

\section{Publisher's Note}

Springer Nature remains neutral with regard to jurisdictional claims in published maps and institutional affiliations.

Ready to submit your research? Choose BMC and benefit from:

- fast, convenient online submission

- thorough peer review by experienced researchers in your field

- rapid publication on acceptance

- support for research data, including large and complex data types

- gold Open Access which fosters wider collaboration and increased citations

- maximum visibility for your research: over $100 \mathrm{M}$ website views per year

At BMC, research is always in progress.

Learn more biomedcentral.com/submissions 